\title{
IMMUNOLOGICAL MONITORING IN TRANSPLANTATION
}

\author{
Lt Col GS CHOPRA*, Col JR BHARDWAJ', \\ Prof NK MEHRA ${ }^{\#}$, Prof SC DASH \\ (Army Hospital Delhi Cantt and All India Institute of Medical Sciences. New Delhi)
}

\begin{abstract}
Sixty eight patients who had undergone live related donor renal transplantation (LRD), were evaluated for soluble interleukin-2 receptors (sIL-2R), tumour necrosis factor alpha (TNF- $\alpha$ ) and autoantibodies against IgG(Fab')2 and IgG(Fc), at pre- and various post-transplant intervals. Serum sIL-2R levels were significantly elevated in hemodialysed patients awaiting transplantation (mean $259.2 \pm 90.5 \mathrm{pmol} / \mathrm{L}$ ) as compared to healthy volunteers (mean $52.6 \pm 16.7 \mathrm{pmol} / \mathrm{L}$ ). In 96 samples obtained from patients with well-functioning grafts (WFG), the post-transplant sIL-2R levels $(135.6 \pm 65.4 \mathrm{pmol} / \mathrm{L})$ were significantly lower $(p<0.001)$ than their pretransplant values. Eight patients with cyclosporin-A (CsA) nephrotoxicity, 14 with reversible acute tubular necrosis (ATN) and 4 patients with partial surgical obstruction, revealed moderate levels $(99.0 \pm 13.7,184.1 \pm$ 47.5, $156.7 \pm 40.4 \mathrm{pmol} / \mathrm{L}$ respectively). On the other hand, 29 patients with acute rejection episodes, 11 with chronic rejection and 8 with infections had significantly higher levels $(307.9 \pm 89.3,253.3 \pm 68.6,345 \pm 110.6$ $\mathrm{pmol} / \mathrm{L}),(\mathrm{p}<0.001)$. TNF- $\alpha$ levels were also raised in rejection and infective episodes but were not statistically significant. Serum anti-IgG(Fab')2 levels were found higher $(0.407$ OD) in WFG as compared to those with declining graft functions ( 0.279 OD). On the contrary high pre- and post-transplant anti-IgG(Fc) activity was associated with increased graft rejection and lower survival rate.
\end{abstract}

MJAFI 1997; 53 : 35-39

KEYWORDS : Autoantibodies; Immunoglobulins; Kidney transplantation; Receptors, Interleukin-2; Transplantation immunology; Tumor necrosis factor.

Introduction

D espite the increasing success of transplantation during recent years, many allografts, regardless of the HLA compatibility between donor and recipient and immunosuppressive therapy, are lost over a period of time. The graft survival can be enhanced by early prediction and detection of graft rejection. The criteria for diagnosis of rejection differs amongst the various transplant teams. A few emphasize clinical and biochemical features while others use histological criteria. Another group prefers cytological and immunohematological parameters. Although histological evaluation of biopsies is considered the gold standard, the exact significance of many morphological changes remains uncertain [1]. Since immunologic processes, like antigen recognition and proliferation of lymphoid cells, mark the beginning of graft dysfunction, their products (cytok- ines and immunoglobulins) appear first in the circulation. Keeping these points in view, sIL-2R, TNF- $\alpha$ and anti-IgG autoantibodies, like anti$\operatorname{lgG}\left(\mathrm{Fab}^{\prime}\right) 2$ and anti-IgG(Fc), were assayed in LRD renal transplantation patients at pre- and various post-transplant periods and findings correlated with their clinical status.

\section{Material and Methods}

\section{Patients}

A total of 68 renal transplant patients from All India Institute of Medical Sciences and Army Hospital Delhi Cantt were included in this study. They were in the age group of 14-61 years (mean $30.2 \pm$ 7.8 years) and all received kidneys from their live related donors like parents, siblings or children. This was confirmed by HLA testing done by standard microlymphocytotoxicity technique [2]. Antidonor antibodies and panel reactive antibodies

*Classified Specialist (Pathology), ${ }^{+}$Senior Adviser (Pathology) Army Hospital Delhi Cantt 110010; "Head of Histocompatibility and Inmunogenetics, "Head of Nephrology, All India Institute Of Medical Sciences, New Delhi. 
were looked for by serological NIH and flowcytometeric crossmatch methods and only patients with no antibodies received transplant.

\section{Estimation of sIL-2R and TNF- $\alpha$}

Two hundred thirty five serial serum samples were obtained from the patients. Samples were collected either 1 day prior to transplantation or at various post-transplant intervals ranging from 3 days to 4 years, which depended upon the clinical state of the patient. Twenty two serum samples from normal healthy individuals served as control. Serum samples were aliquoted and kept frozen at $-20^{\circ} \mathrm{C}$ until assay time so as to avoid repeated freezing and thawing. The assays were performed with commercial kits (M/s Boehringer Mannheim Bio-chemica, Germany) based on sandwich enzyme immunoassay technique using two monoclonal antibodies against sIL-2R and TNF- $\alpha$. The levels were calculated using standard concentrations with the help of computerized laboratory data system using Anthos HTII ELISA reader.

\section{Estimation of anti-IgG(Fab')2 and anti-IgG(Fc)}

For the determination of anti-IgG(Fab')2 and anti-IgG(Fc) levels, commercial monoclonals (M/s Jackson Immunoresearch Laboratories, USA) were used. The levels were estimated using sandwich enzyme immunoassay. Prior checkerboard titration of various antibodies was carried out to get the optimum results.

\section{Statistical Analysis}

To find the significance of difference between each of the groups, nonparametric multiple range test (3) was applied and a p value of less than 0.05 was considered significant.

\section{Post-transplant follow-up}

Various graft dysfunctions like rejection episodes, acute tubular necrosis (ATN), CsA nephrotoxicity and infective episodes were diagnosed clinically assisted by standard biochemical and microbiological techniques. Biopsy was performed wherever necessary.

Results

Serum sIL-2R levels

Serum sLL-2R levels were significantly elevated in 64 hemodialysed patients awaiting trans- plantation (mean $259 \pm 90.5 \mathrm{pmol} / \mathrm{L}$ ) in contrast to those of healthy volunteers $(52.6 \pm 16.7 \mathrm{pmol} / \mathrm{L})$ (Table 1). In 96 serial serum samples from patients with well-functioning grafts (WFG), the levels were significantly reduced $(135.6 \pm 65.4 \mathrm{pmol} / \mathrm{L})$ as compared to their pretransplant levels ( $p<$ 0.001). On the other hand, patients with CsA nephrotoxicity, reversible ATN and partial surgical obstruction revealed moderately elevated levels (Table 2). However in a few transplant cases comparatively low levels were found before, after and during rejection.

TABLE 1

sIL-2R levels in renal graft dysfunctions

\begin{tabular}{lcrcrr}
\hline Sample & $\begin{array}{l}\text { No. of } \\
\text { samples }\end{array}$ & \multicolumn{3}{c}{ Il-2R (pmol/L) } \\
\cline { 3 - 5 } & Mean & \pm & SD & Range \\
\hline Normal control & 22 & 52.6 & \pm 16.7 & $25-90$ \\
Haemodialysed & 64 & 259.2 & \pm 90.5 & $100-450$ \\
Well functioning & 96 & 135.6 & \pm 65.4 & $70-260$ \\
$\quad$ graft & & & & & \\
Acute rejection & 29 & 307.9 & \pm 89.3 & $115-510$ \\
Chronic rejection & 11 & 253.3 & \pm 68.6 & $110-336$ \\
\hline
\end{tabular}

TABLE 2

sIL-2R levels in renal graft dysfunctions

\begin{tabular}{|c|c|c|c|c|}
\hline \multirow{2}{*}{ Sample } & \multirow{2}{*}{$\begin{array}{l}\text { No of } \\
\text { samples }\end{array}$} & \multicolumn{3}{|c|}{ IL-2R (pmol/L) } \\
\hline & & Mean & $\pm \mathrm{SD}$ & Range \\
\hline Normal control & 22 & 52.6 & \pm 16.7 & $25-90$ \\
\hline CsA nephrotoxicity & 8 & 99.0 & \pm 13.7 & $80-110$ \\
\hline Infections & 8 & 345.0 & \pm 110.6 & $200-550$ \\
\hline Reversible ATN & 14 & 184.1 & \pm 47.5 & $105-240$ \\
\hline Irreversible ATN & 2 & 330.0 & $\pm \quad 14.1$ & $320-340$ \\
\hline $\begin{array}{l}\text { Partial surgical } \\
\text { obstruction }\end{array}$ & 3 & 156.7 & $\pm \quad 40.4$ & $110-180$ \\
\hline
\end{tabular}

\section{TNF- $\alpha$ assays}

TNF- $\alpha$ levels were found to be low or sometimes undetectable in healthy controls $(0.45 \pm 67$ $\mathrm{pg} / \mathrm{mL})$, pretransplant samples (10.2 \pm 4.80 $\mathrm{pg} / \mathrm{mL})$, WFG (8.66 $\pm 7.82 \mathrm{pg} / \mathrm{mL})$, ATN (3.54 \pm $3.16 \mathrm{pg} / \mathrm{mL}), \mathrm{CsA}$ nephrotoxicity (2.76 \pm 2.45 $\mathrm{pg} / \mathrm{mL})$, surgical obstruction $(5.51 \pm 3.49 \mathrm{pg} / \mathrm{mL})$ (Fig 1). In a few cases of graft rejection and infection the levels were however found to be quite high $(121.7 \pm 399.2 \mathrm{pg} / \mathrm{mL}$, range $16-1500 \mathrm{pg} / \mathrm{mL})$ 
TUMOUR NECROSIS FACTOR - ALPHA LEVELS

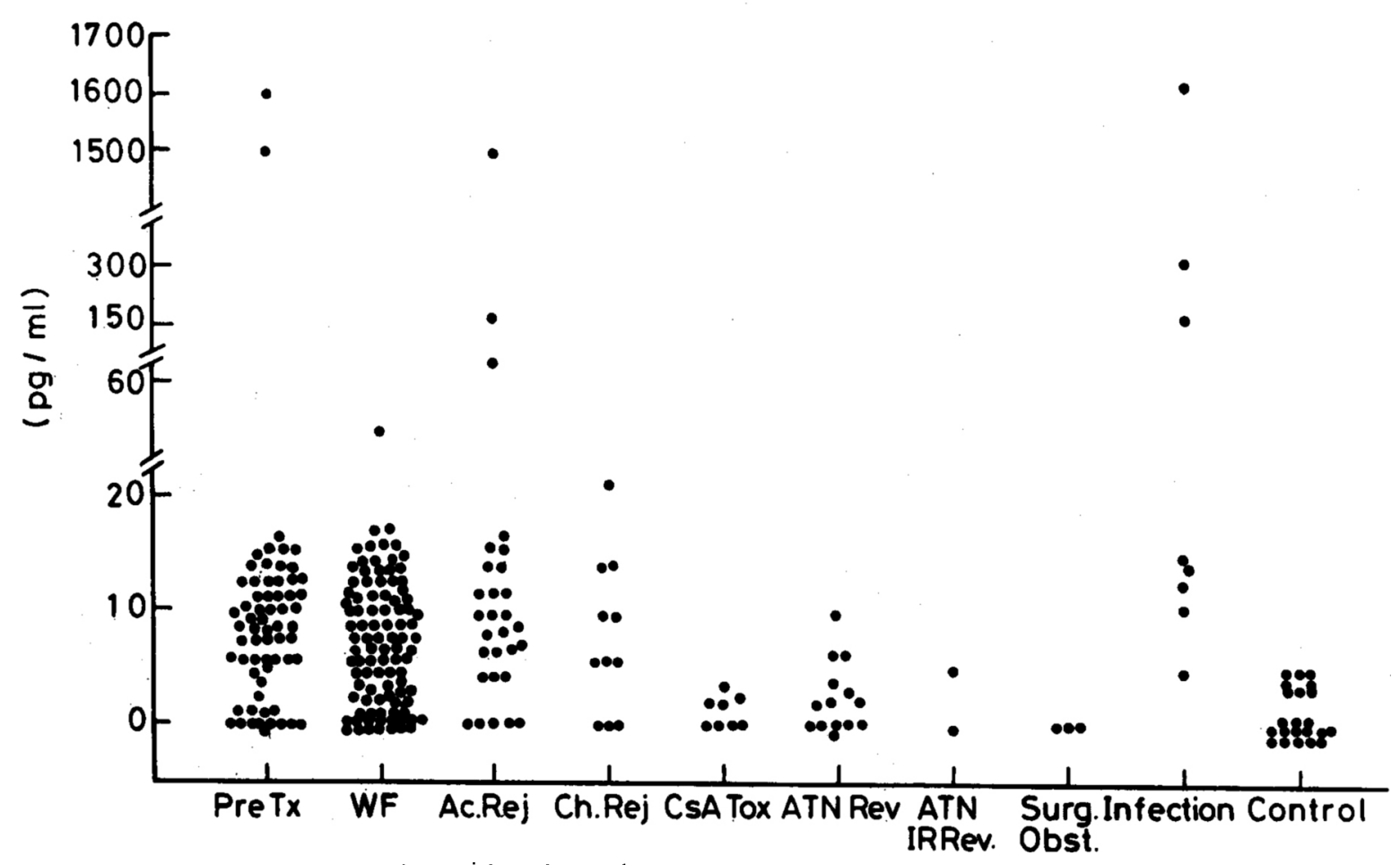

Fig. 1: Shows scatter diagram of TNF- $\dot{\alpha}$ in various patient groups.

and $(190.69 \pm 446.14$, range $5-1620 \mathrm{pg} / \mathrm{mL})$.

\section{Anti-IgG autoantibodies}

Higher levels of anti-IgG(Fab')2 antibody were found in dialysed patients as compared to healthy controls. Patients with WFG also exhibited higher levels at both pre- and post-transplant periods as compared to those undergoing rejection (Fig 2a \& 2b). In contrast lower pretransplant levels of anti$\operatorname{IgG}(\mathrm{Fc})$ antibodies were observed in patients with WFG as compared to cases with graft dysfunction (Fig 3a). The same phenomenon, however, was not consistently seen in post-transplant serum samples (Fig.3b).

\section{Discussion}

Cytokines are mediators of cellular communication and there has been extraordinary development in this field in the last decade. They are major components of specific and humoral immunoresponses and of their effector mechanisms. In addition, as targets of immunosuppressive agents, they also play a central role in transplant- recipient defence against infectious episodes and tumours [4]. Anti-immunoglobulin antibodies represent an entire class of autoantibodies of distinct isotypes, specificities and conceivably of different functions and their presence has been studied in many transplant situations [5].

The expression of sIL-2R is essential for triggering the $\mathrm{T}$ cell clonal proliferation leading to the generation of effector cells and release of cytokines. The increased sIL-2R levels in pretransplant haemodialysed patients in our study is possibly due to activation of complement (c5a) or monocyte or macrophages by direct.contact with dialyzer membrane thus causing increased cytokine release [6]. The present study also shows that serum sIL-2R levels are raised during graft rejection as compared to the WFG, CsA nephrotoxicity and ATN (Table 1,2). The finding is in agreement with other studies conducted mainly on cadaver or unrelated transplantation [7-9]. The levels were, however, found to be comparatively lower in our study possibly due to low immunological stimulus in LRD patients. The serum sIL-2R levels were 
IgG ANTI-F(ab)2 ANTIBODIES PRE TRANSPLANT LEVELS

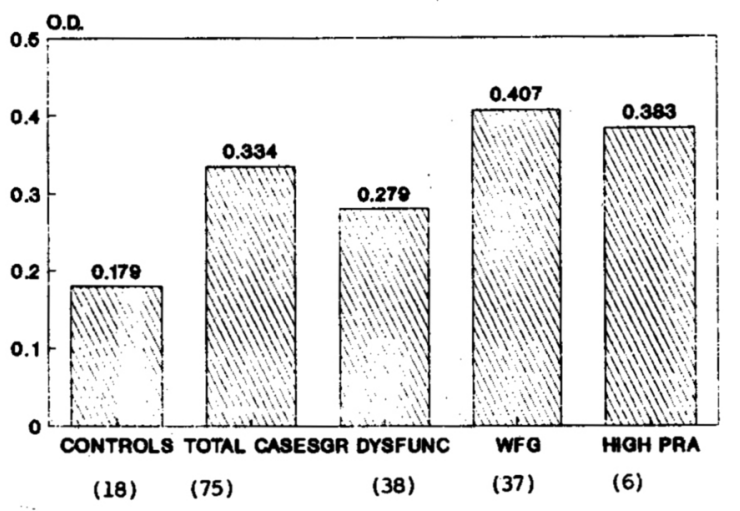

IgG ANTI-F(ab)2 ANTIBODIES POST TRANSPLANT LEVELS

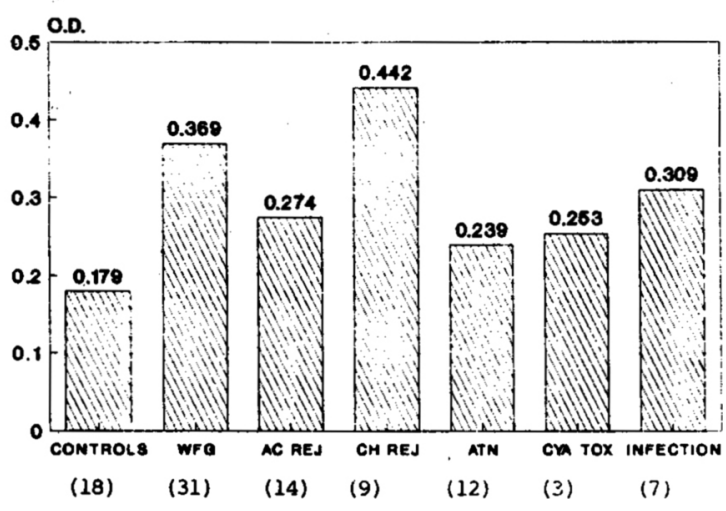

Fig. 2a \& $b$ :Shows levels of pre- and post-transplant levels of anti-IgG(Fab')2.

also found to be raised in infections and in primary graft dysfunction leading to irreversible ATN. The serial assays done at pre- and various post-transplant periods gave a clear picture of the rise in SIL-2R levels at the time of graft rejection or infection (Fig 1). The levels were found to be reduced after antirejection therapy. Serial assays were found to be more important as some individuals had consistently low levels at pre- and post-transplant periods and thus at the time of rejection their sIL-2R levels were lower than in other rejection cases (Fig.1). In our study it was difficult to differentiate rejection episodes from infection since both these conditions stimulate the immune system and trigger cytokine release [7].

TNF- $\alpha$, a cytokine produced mainly by monocyte-macrophages with a wide range of biological effects, is responsible for systemic reactions like

\section{IgG ANTI-FC ANTIBODIES \\ PRE TRANSPLANT}
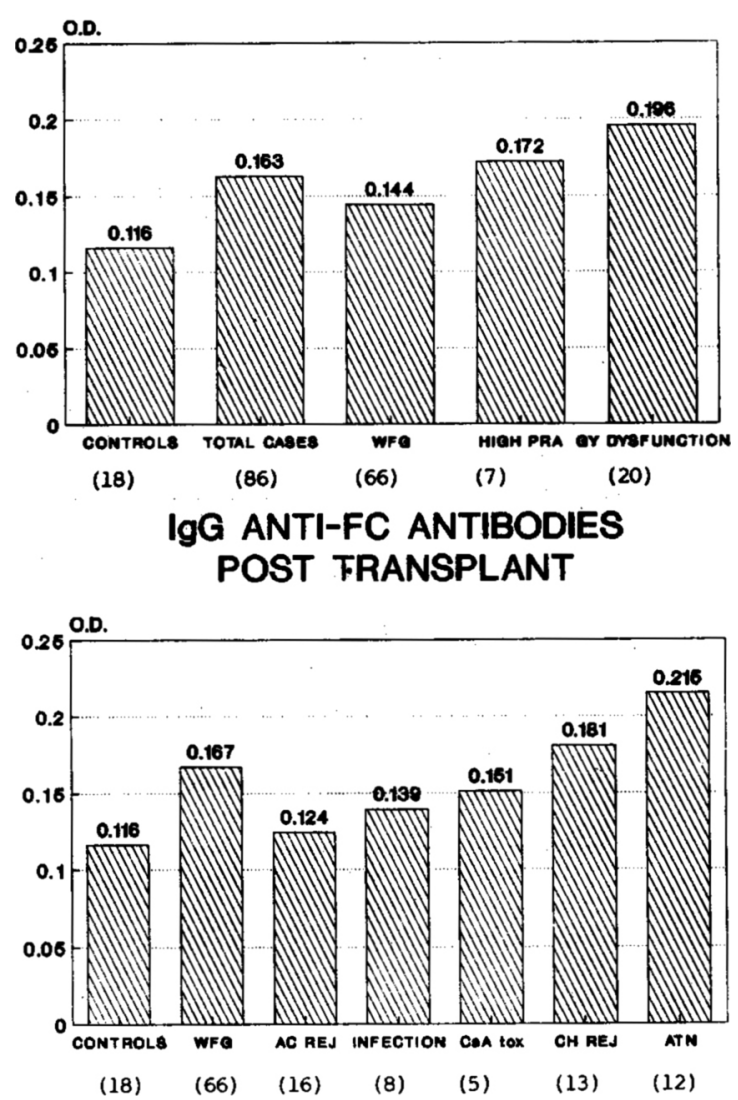

Fig. $3 a$ \& $b$ : Shows levels of pre- and post-transplant levels of anti-IgG(Fc).

fever. Production of TNF- $\alpha$ is important in T cell activation. It can also increase the expression of major histocompatibility complex (MHC) class I antigens on endothelial cells [7]. So via these mechanisms TNF- $\alpha$ can contribute to cellular injury which occurs during rejection. In our study, TNF- $\alpha$ levels were not found to be of much use in monitoring post-transplant graft functions. This was because of undetectable, very low or overlapping levels in different post-transplant conditions (Fig 1). This may again be due to low stimulation of TNF- $\alpha$ in LRD patients as compared to higher and significant levels found in cadaver transplantation [10]. In this context it is significant to note that levels were found to be highly raised in few patients both at pre- and post-transplant periods. Whether this was due to some other immunological process not connected with transplantation is 
not clear.

In our study, WFG patients showed higher levels of anti-IgG(Fab')2 in both pre- and post-transplant serum samples (Fig $2 \mathrm{a} \& 2 \mathrm{~b}$ ). Similarly higher post-transplant levels were seen in patients with chronic rejection. However, the levels were found to be lower in acute rejection as well as ATN cases. This may indicate a protective role of these antibodies on kidney graft survival. Various studies on cadaver transplantation have hypothesized different immunological processes but no consensus has been established [5]. Inversely the anti-IgG(Fc) antibody levels were found to be higher in graft dysfunction cases in pretransplant serum samples. The same phenomenon was however not consistently seen in the post-transplant samples.

We conclude that immunological monitoring in transplantation at various pre- and post-transplant situations can give valuable information. It should be conducted more frequently, in conjunction with other histological and biochemical investigations, so as to come to a reasonable conclusion about graft function.

\section{REFERENCES}

1. Hammer $\mathrm{C}$, Reichenspurner $\mathrm{H}$, Klima $\dot{\mathrm{G}}$. Immunologic pa- rameters for the diagnosis of graft rejection. Transplant Proc 1993; 25: 26-9.

2. Terasaki PI, McClelland JD. Microdroplet assay of human serum cytoxins. Nature 1964; 204: 998-1000.

3. Conover WJ. Practical non-parametric statistics. Second edition. New York: Wiley, 1980; 213-19.

4. Soulillou JP. Cytokines and Transplantation. Transplant Proc 1993; 25: 106-8.

5. Susal C, Groth J, Oberg $\mathrm{HH}$, et al. The association of kidney graft outcome with pre-transplant serum antiIgG(Fab')2 gamma activity. Transplantation 1992; 54: 632-35.

6. Herbatin A, Nguyen AT, Zingraft J, et al. Influence of uraemia and haemodialysis on circulating interleukin-1 and tumour necrosis factor alpha. Kidney Int 1990; 37: 116-8.

7. Noronha IL, Daniel V, Mohring $K$, et al. Analysis of plasma interleukin-2 receptor (sIL-2R) and tumour necrosis factor-alpha (TNF- $\alpha$ ) in renal transplant patients. Clin Transplantation 1992; 6: 272-84.

8. Plazza JJ, Blum G, Ortiz A, et al. Usefulness of serum interleukin-2 receptor levels in renal allograft recipients. Transplant Proc 1992; 24: 63-4.

9. Beksac M, Dalva K, Gonenc F, et al. Soluble CD23 and interleukin-2 receptor levels in renal allograft recipients. Transplant Proc 1993; 25: 2145-7.

10. Bubnova LN, Kabakov $A$, Serebrianaya $N$, et al. Interleukin-1b and tumour necrosis factor-a serum levels in renal allograft recipients. Transplant Proc 1992; 24: 2545. 